\title{
Neuroprotection and spatial memory enhancement of four herbal mixture extract in HT22 hippocampal cells and a mouse model of focal cerebral ischemia
}

Sung Min Ahn ${ }^{1,7}$, Yu Ri Kim ${ }^{1}$, Ha Neui Kim¹, Young Whan Choi ${ }^{2,7}$, Jae Won Lee ${ }^{3,7}$, Cheol Min Kim ${ }^{4,7}$, Jin Ung Baek ${ }^{5}$, Hwa Kyoung Shin ${ }^{6,7}$ and Byung Tae Choi ${ }^{1,6,7^{*}}$

\begin{abstract}
Background: Four traditional Korean medicinal herbs which act in retarding the aging process, Polygonum multiflorum Thunb., Rehmannia glutinosa (Gaertn) Libosch., Polygala tenuifolia Willd., and Acorus gramineus Soland., were prepared by systematic investigation of Dongeuibogam (Treasured Mirror of Eastern Medicine), published in the early 17th century in Korea. This study was performed to evaluate beneficial effects of four herbal mixture extract (PMC-12) on hippocampal neuron and spatial memory.
\end{abstract}

Methods: High performance liquid chromatography (HPLC) analysis was performed for standardization of PMC-12. Cell viability, lactate dehydrogenase, flow cytometry, reactive oxygen species (ROS), and Western blot assays were performed in HT22 hippocampal cells and immunohistochemistry and behavioral tests were performed in a mouse model of focal cerebral ischemia in order to observe alterations of hippocampal cell survival and subsequent memory function.

Results: In the HPLC analysis, PMC-12 was standardized to contain $3.09 \%$ 2,3,5,4'-tetrahydroxystillbene-2-O- $\beta$-D-glucoside, $0.35 \%$ 3,6-disinapoyl sucrose, and $0.79 \%$ catalpol. In HT22 cells, pretreatment with PMC-12 resulted in significantly reduced glutamate-induced apoptotic cell death. Pretreatment with PMC-12 also resulted in suppression of ROS accumulation in connection with cellular $\mathrm{Ca}^{2+}$ level after exposure to glutamate. Expression levels of phosphorylated p38 mitogen-activated protein kinases (MAPK) and dephosphorylated phosphatidylinositol-3 kinase (PI3K) by glutamate exposure were recovered by pretreatment with either PMC-12 or anti-oxidant N-acetyl-L-cysteine (NAC). Expression levels of mature brain-derived neurotrophic factor (BDNF) and phosphorylated cAMP response element binding protein (CREB) were significantly enhanced by treatment with either PMC-12 or NAC. Combination treatment with PMC-12, NAC, and intracellular $\mathrm{Ca}^{2+}$ inhibitor BAPTA showed similar expression levels. In a mouse model of focal cerebral ischemia, we observed higher expression of mature BDNF and phosphorylation of CREB in the hippocampus and further confirmed improved spatial memory by treatment with PMC-12.

Conclusions: Our results suggest that PMC-12 mainly exerted protective effects on hippocampal neurons through suppression of $\mathrm{Ca}^{2+}$-related ROS accumulation and regulation of signaling pathways of p38 MAPK and PI3K associated with mature BDNF expression and CREB phosphorylation and subsequently enhanced spatial memory.

Keywords: Hippocampal cell, Neuroprotection, Memory, Polygonum multiflorum

\footnotetext{
* Correspondence: choibt@pusan.ac.kr

${ }^{1}$ Department of Korean Medical Science, School of Korean Medicine, Pusan

National University, Yangsan 626-870, Republic of Korea

${ }^{6}$ Division of Meridian and Structural Medicine, School of Korean Medicine,

Pusan National University, Yangsan 626-870, Republic of Korea

Full list of author information is available at the end of the article
} 


\section{Background}

Due to an increase in life expectancy and the elderly population, memory and cognitive impairments including dementia have become a major public health problem [1]. Hippocampal neuronal death is a major factor in the progress of memory impairment in many brain disorders $[2,3]$. Prevention of hippocampal neuronal deaths provides a potential new therapeutic strategy to ameliorate memory and cognitive impairment of many neurological disorders. HT22 hippocampal cell line, which lacks a functional glutamate receptor, is valuable for studying molecular mechanism of memory deficits $[2,4]$.

Exposure of HT22 hippocampal cells to glutamate shows neurotoxicity through oxidative stress rather than $\mathrm{N}$-methyl-D-aspartate receptor-mediated excitotoxicity [5-7]. Non-receptor-mediated oxidative stress involves inhibition of cysteine uptake, alterations of intracellular cysteine homeostasis, glutathione depletion, and ultimately elevation of reactive oxygen species (ROS) activation inducing neuronal cell death [5, 8-10]. Death of hippocampal cell following oxidative stress and accumulation of ROS play a role in learning and memory impairment of brain disorders [11].

Under oxidative neuronal death, the pathways of p38 mitogen-activated protein kinase (MAPK) and phosphatidylinositol-3 kinase (PI3K) play critical roles in control of neuronal death and cell survival caused by glutamate, respectively $[6,12]$. Brain-derived neurotrophic factor (BDNF) mediates neuronal survival and neuroplasticity and associated learning and memory, and its signaling is associated with alteration of the main mediators of PI3K pathways [13-15]. Cyclic AMP response element binding protein (CREB) has multiple roles in different brain areas, as well as promotion of cell survival $[16,17]$ and is involved in memory, learning, and synaptic transmission in the brain $[18,19]$.

Studies of the neuroprotection have been performed in both HT22 cells and middle cerebral artery occlusion (MCAO)-induced injury [20, 21]. However memory deficits are also frequently noted after stroke. Transient MCAO induce a progressive deficiency in spatial performance related to impaired hippocampal function [22]. Thus shorter durations of ischemia have been used in the experiments that aimed to test impaired spatial learning and memory performance [23].

In traditional literature of Korean/Chinese medicine, research for screening, evaluating citation and attempting practical use of herbs has been conducted for development of therapeutic strategies [24]. We prepared multiherb formulae comprising the roots of Polygonum multiflorum, Rehmannia glutinosa, Polygala tenuifolia, and Acorus gramineus to increase medicinal efficacy by systematic investigation of Dongeuibogam, published by Joon Hur in the early 17th century in Korea. Our aim was to determine the beneficial effects of herbal mixture extract on hippocampal neurons, a susceptible cell important in memory impairment, in HT22 hippocampal cells and the hippocampus with subsequent memory enhancement in a mouse model of focal cerebral ischemia.

\section{Methods}

\section{Chemicals and antibodies}

L-glutamate, 3-(4,5-dimethylthiazol-2-yl)-2,5-diphenyltetrazolium bromide (MTT), N-acetyl-L-cysteine (NAC), and $\beta$-actin antibody were purchased from SigmaAldrich (St. Louis, MO, USA). BAPTA-AM and EGTA were purchased from Tocris Bioscience (Ellisville, MO, USA). Dulbecco's modified Eagle's medium (DMEM), fetal bovine serum (FBS), and other cell culture reagents were purchased from Gibco-Invitrogen (Carlsbad, CA, USA). Antibodies recognizing p38, phospho-p38 (pp38, Thr180/Tyr182), PI3K, and pro-BDNF were supplied by Santa Cruz Biotechnology (Santa Cruz, CA, USA), and CREB, phospho-CREB (pCREB, Ser133), and phosphoPI3K (pPI3K, Tyr458) were supplied by Cell Signaling (Danvers, MA, USA). Antibody recognizing neuronal nuclei (NeuN) was supplied by Millipore Corporation (Billerica, MA, USA), and mature BDNF was supplied by Abcam (Cambridge, MA, USA). Secondary antibodies were supplied by Santa Cruz Biotechnology. A FITC Annexin $\mathrm{V}$ apoptosis detection kit was purchased from BD Bioscience (San Diego, CA, USA). A lactate dehydrogenase (LDH) cytotoxicity assay kit was purchased from Promega (Madison, WI, USA), and ROS detection reagent, 5-(and-6)-carboxy-2',7'-dichlorodihydrofluorescein diacetate (carboxy- $\mathrm{H}_{2}$ DCFDA), and Hoechst 33342 was purchased from Invitrogen (Carlsbad, CA, USA).

\section{Preparation of four herbal mixture extract}

The dried roots of Polygonum multiflorum Thunb., Rehmannia glutinosa (Gaertn) Libosch., Polygala tenuifolia Willd., and Acorus gramineus Soland. were purchased from Dongnam Co. (Busan, Korea) and were authenticated by Professor Y.W. Choi, Department of Horticultural Bioscience, College of Natural Resource and Life Science, Pusan National University. A voucher specimen (accession number PMCWSD2.1 2.4) was deposited at the Plant Drug Research Laboratory of Pusan National University (Miryang, Korea). Dried powdered Polygonum multiflorum (25.5 kg), Rehmannia glutinosa $(9.5 \mathrm{~kg})$, Polygala tenuifolia $(7.5 \mathrm{~kg})$, and Acorus gramineus roots $(7.5 \mathrm{~kg})$ were immersed in $450 \mathrm{~L}$ of distilled water and boiled at $120 \pm 5{ }^{\circ} \mathrm{C}$ for $150 \mathrm{~min}$. The resultant extract was centrifuged $(2000 \times g$ for $20 \mathrm{~min}$ at $4{ }^{\circ} \mathrm{C}$ ) and filtered through a $0.2-\mu \mathrm{m}$ filter. The filtrate was then concentrated in vacuo at $70 \pm 5{ }^{\circ} \mathrm{C}$ under reduced pressure and then converted into a fine spraydried powder at a yielding rate of $4.6 \%(2.3 \mathrm{~kg})$ in a 
vacuum drying apparatus. Finally, the solid form of the spray-dried powder was dissolved with dimethyl sulfoxide (DMSO) for use as PMC-12 in experiments.

\section{High performance liquid chromatography (HPLC) analysis and quantification}

For analysis of quality and quantity for PMC-12, sample of $0.5 \mathrm{~g}$ dry weight was sonicated in $10 \mathrm{ml} \mathrm{MeOH}$, filtered through a $0.45 \mu \mathrm{m}$ membrane filter before HPLC analysis. HPLC using G1100 systems (Agilent Technologies, Waldbronn, Germany) was performed on a Luna $\mathrm{C}_{18}$ column $(5 \mu \mathrm{m}, 150 \mathrm{~mm} \times 3.0 \mathrm{~mm}$ i.d. Phenomenex, Torrance, CA, USA) with a mobile phase gradient of acetonitrile-water (0 to 100) for $35 \mathrm{~min}$. The injection volume was $10 \mu \mathrm{l}$ of sample and mobile phase flow rate $0.4 \mathrm{ml} / \mathrm{min}$ with $\mathrm{UV}$ detection at $254 \mathrm{~nm}$ for 2,3,5,4' -tetrahydroxystilbene-2-O- $\beta$-D-glucoside (THS) and $3^{\prime}, 6$-disinapoyl sucrose (DISS) and at $203 \mathrm{~nm}$ for catalpol. Acquisition and analysis of chromatographic data were performed using Agilent chromatographic Work Station software (Agilent Technologies). Stock solutions of THS, DISS, and catalpol were prepared for quantification of PMC-12. The contents of PMC-12 were determined by regression equations, calculated in the form of $y=a x+b$, where $x$ and $y$ were peak area and contents of the compound. The limits of detection (LOD) and quantification (LOQ) under the current chromatographic conditions were determined at a signal-to-noise ratio of 3 and 10, respectively.

\section{Cell culture}

HT22 cells were cultured in DMEM supplemented with $10 \% \mathrm{FBS}$ and $1 \%$ penicillin/streptomycin in a $5 \% \mathrm{CO}_{2}$ humidified incubator at $37{ }^{\circ} \mathrm{C}$. The cells were incubated for $24 \mathrm{~h}$ prior to experimental treatments. After incubation, cells were treated with various concentrations of PMC-12 for $24 \mathrm{~h}$, followed by exposure to $5 \mathrm{mM}$ glutamate for $24 \mathrm{~h}$. Cells were pretreated with inhibitors for 30 min before addition of PMC-12 and then exposed to glutamate.

\section{Cell viability assay}

HT22 cell survival was assessed using a MTT assay. The culture medium was replaced with $0.5 \mathrm{mg} / \mathrm{ml} \mathrm{MTT} \mathrm{solu-}$ tion and then left in a dark place for $4 \mathrm{~h}$ at $37{ }^{\circ} \mathrm{C}$. Following incubation, the cells were treated with DMSO in order to dissolve the formazan crystals. Absorbance was determined at $595 \mathrm{~nm}$ using a SpectraMax 190 spectrophotometer (Molecular Devices, Sunnyvale, CA, USA). Results were expressed as a percentage of control.

\section{Determination of cell cytotoxicity}

Released LDH from damaged cells was measured for estimation of cytotoxicity. For induction of maximal cell lysis, treated cells were lysed with $0.9 \%$ Triton X-100 for $45 \mathrm{~min}$ at $37{ }^{\circ} \mathrm{C}$. Supernatant samples were transferred to a 96-well enzymatic assay plate and reacted with substrate mix in the dark for $30 \mathrm{~min}$ at room temperature. At the end of that time, samples were treated with stop solution and read at $490 \mathrm{~nm}$ using a SpectraMax 190 spectrophotometer (Molecular Devices). Data represent the percentage of LDH released relative to controls.

\section{Flow cytometric analysis}

After treatment, cells were harvested and resuspended in binding buffer at a concentration of $1 \times 10^{4}$ cells $/ \mathrm{ml}$. For analysis of cell death types, $100 \mu \mathrm{l}$ of the solution was transferred to a flow cytometric tube, followed by incubation with Annexin V-FITC and propidium iodide (PI) in the dark at room temperature for $15 \mathrm{~min}$. Subsequently, $400 \mu \mathrm{l}$ of binding buffer was added and analysis of the samples was performed using a flow cytometer (FACS Canto $^{\text {тм }}$ II; Becton-Dickinson, San Jose, CA, USA).

\section{ROS measurement}

HT22 cells were cultured in 96-well white plates at a density of $5 \times 10^{3}$ cells per well. After adherence, cells were pretreated with PMC-12 for $24 \mathrm{~h}$ and then exposed to $5 \mathrm{mM}$ glutamate for $24 \mathrm{~h}$. Treated cells were washed with PBS. Carboxy- $\mathrm{H}_{2}$ DCFDA $(20 \mu \mathrm{M})$ (Invitrogen) was applied to the cells, followed by incubation for $1 \mathrm{~h}$ in a $37{ }^{\circ} \mathrm{C}$ incubator. Fluorescence was measured using a Mutilabel counter (Perkin Elmer 1420, MA, USA). Accumulation of intracellular ROS was observed and photographed under a fluorescence microscope (Carl Zeiss Imager M1, Carl Zeiss, Inc., Gottingen, Germany). In addition, cells were harvested, resuspended in $1 \mathrm{ml}$ PBS with $20 \mu \mathrm{M}$ carboxy$\mathrm{H}_{2}$ DCFDA (Invitrogen), and then incubated for $1 \mathrm{~h}$ at $37^{\circ} \mathrm{C}$. After washing, cellular fluorescence was measured using a flow cytometer.

\section{Nuclear staining with Hoechst 33342}

Apoptosis was investigated by staining the cells with Hoechst 33342 (Invitrogen). HT22 cells were washed three times with PBS and then fixed in PBS containing $4 \%$ paraformaldehyde for $25 \mathrm{~min}$ at $4{ }^{\circ} \mathrm{C}$. Fixed cells were washed with PBS and stained with Hoechst $33342(10 \mu \mathrm{g} / \mathrm{ml})$ for $15 \mathrm{~min}$ at room temperature. The cells were washed three times with PBS and mounted using the medium for fluorescence (Vector Laboratories, Inc.) The cells were observed under a fluorescence microscope for nuclei showing typical apoptotic features such as chromatin condensation and fragmentation. Photographs were taken at a magnification of X 200 . 


\section{Western blot analysis}

The cells were homogenized with lysis buffer [200 mM Tris ( $\mathrm{pH}$ 8.0), $150 \mathrm{mM} \mathrm{NaCl}, 2 \mathrm{mM}$ EDTA, $1 \mathrm{mM} \mathrm{NaF}$, $1 \% \mathrm{NP} 40,1 \mathrm{mM}$ PMSF, $1 \mathrm{mM} \mathrm{Na} \mathrm{VO}_{4}$, protease inhibitor cocktail]. Equal amounts of proteins were separated by 10 or $12 \%$ sodium dodecyl sulfate-polyacrylamide gel electrophoresis (SDS-PAGE) and then transferred to a nitrocellulose membrane (Whatman $\mathrm{GmbH}$, Dassel, Germany). The membranes were blocked with $5 \%$ skim milk in PBST for $1 \mathrm{~h}$, followed by overnight exposure to appropriate antibodies. Membranes were then incubated with appropriate horseradish peroxidase-conjugated antibodies for $1 \mathrm{~h}$. All specific bands were visualized using an enhanced chemiluminescence system (Pierce Biotech, Rockford, IL, USA) and imaged using an Image Quant LAS-4000 imaging system (GE Healthcare Life Science, Uppsala, Sweden). Results of the Western blot assay reported here are representative of at least three experiments.

\section{Focal cerebral ischemia}

To confirm beneficial effects of PMC-12 on hippocampal cell, we used middle cerebral artery occlusion (MCAO) model. Male C57BL/6 mice (20-25 g) were obtained from Dooyeol Biotech (Seoul, Korea). The mice were housed at $22{ }^{\circ} \mathrm{C}$ under alternating $12 \mathrm{~h}$ cycles of dark and light, and were fed a commercial diet and allowed tap water ad libitum. All experiments were approved by the Pusan National University Animal Care and Use Committee. Each group consisted of six mice and all treatments were administered under isoflurane (Choongwae, Seoul, Korea) anesthesia, which was provided using a calibrated vaporizer (Midmark VIP3000, Orchad Park, OH, USA).

Focal cerebral ischemia was induced by occluding the middle cerebral artery (MCA) using the intraluminal filament technique. A fiber-optic probe was affixed to the skull over the middle cerebral artery for measurement of regional cerebral blood flow using a PeriFlux Laser Doppler System 5000 (Perimed, Stockholm, Sweden). Middle cerebral artery occlusion model was induced by a silicon-coated 4-0 monofilament in the internal carotid artery and the monofilament was advanced to occlude the MCA. The filament was withdrawn $30 \mathrm{~min}$ after occlusion and reperfusion was confirmed using laser Doppler. Mice in the PMC-12 groups received oral administration daily at the doses of 100 and $500 \mathrm{mg} / \mathrm{kg}$ for three weeks after MCAO, while mice in the control and vehicle groups were only given distilled water at the same intervals.

\section{Immunofluorescence staining}

Mice anesthetized with isoflurane received intracardial perfusion with saline and then $4 \%$ paraformaldehyde in PBS. Brains were removed, post-fixed in the same fixative for $4 \mathrm{~h}$ at $4{ }^{\circ} \mathrm{C}$, and immersed in $30 \%$ sucrose for $48 \mathrm{~h}$ at $4{ }^{\circ} \mathrm{C}$ for cryoprotection. Frozen $20 \mu \mathrm{m}$-thick sections were incubated for blocking with a blocking buffer (1X PBS/5 \% normal serum/0.3 \% Triton X-100) for $1 \mathrm{~h}$ at room temperature. The sections were incubated with

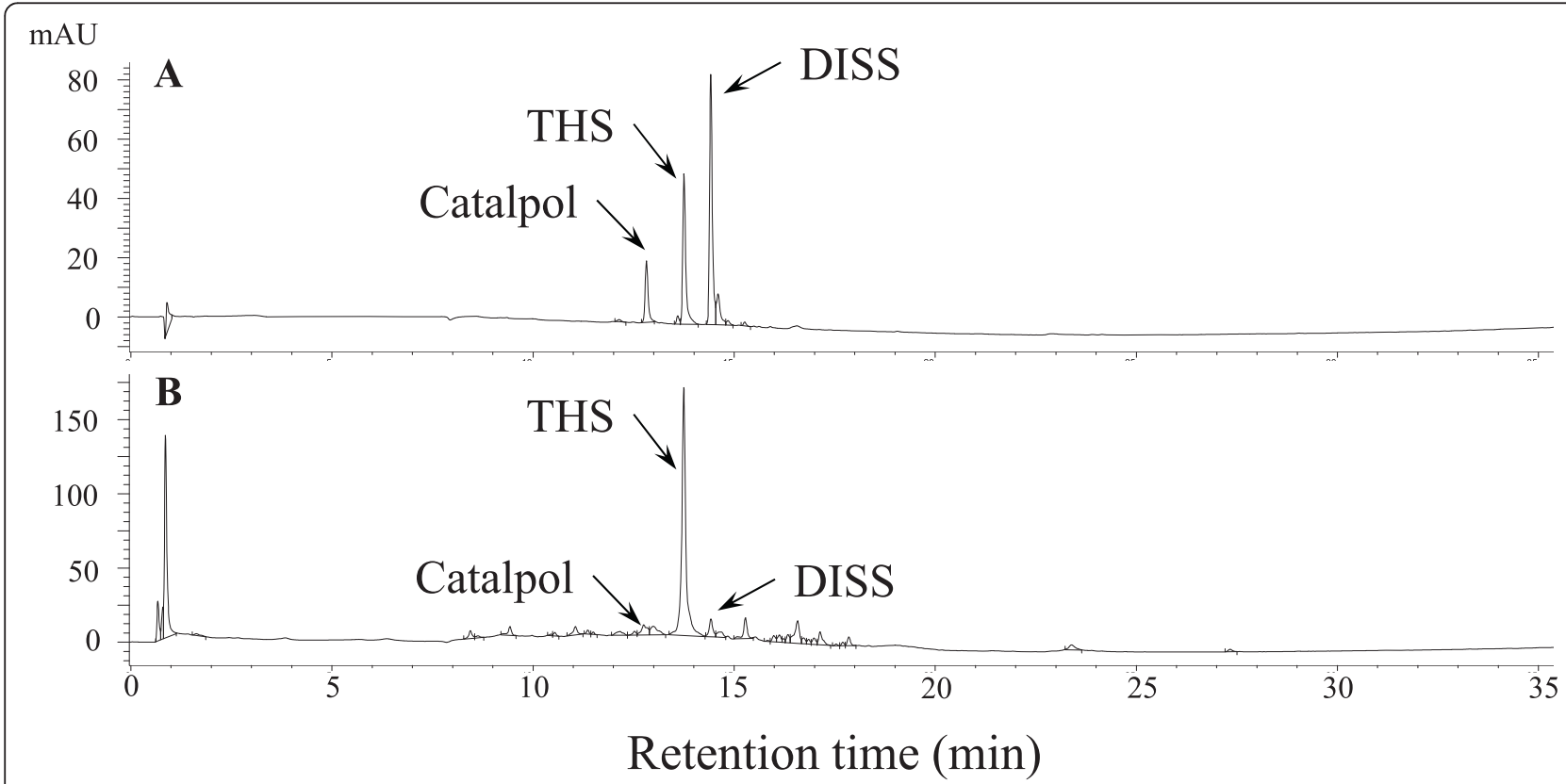

Fig. 1 HPLC analysis and quantification of PMC-12. HPLC chromatograms of THS, DISS, and catalpol reference (a) and PMC-12 (b) obtained using a Luna C18 (2) column monitored at $254 \mathrm{~nm}$ and eluted with $100 \%$ water to $100 \%$ acetonitrile for 40 at a flow-rate of $1.0 \mathrm{ml} / \mathrm{min}$ 
Table 1 Concentration, calibration curve, regression data, LODs and LOQs for THS, DISS, and catalpol by HPLC

\begin{tabular}{lllllll}
\hline Compounds & Wavelength $(\mathrm{nm})$ & Concentration (\%) & Calibration curve & $r^{2}$ & $L O D(\mu \mathrm{g} / \mathrm{ml})$ & $\mathrm{LOQ}(\mu \mathrm{g} / \mathrm{ml})$ \\
\hline THS & 254 & $3.085 \pm 0.271$ & $\mathrm{y}=3284.72 x+2.00$ & 0.999 & 1.41 & 4.27 \\
DISS & 254 & $0.352 \pm 0.058$ & $\mathrm{y}=4289.06 x+47.95$ & 0.999 & 0.59 & 1.79 \\
Catalpol & 203 & $0.785 \pm 0.059$ & $\mathrm{y}=1253.49 x+31.37$ & 0.999 & 0.63 & 1.91 \\
\hline
\end{tabular}

the following primary antibodies to NeuN (Millipore Corporation), mature BDNF (Abcam), and pCREB (Cell Signaling) overnight in $\mathrm{PBS}$ at $4{ }^{\circ} \mathrm{C}$. After washes with PBS, the sections were incubated with the fluorescent secondary antibody (Vector Laboratories, Inc., Burlingame, CA, USA) at room temperature in the dark, respectively, and then washed three times with PBS. Subsequently, slides were mounted in the mounting medium (Vector Laboratories, Inc.) and captured using a fluorescence microscope.

\section{Behavioral assessment}

Acquisition training for the Morris water maze was performed on four consecutive days from 10 days to seven days before MCAO (five trials per day) and basal time was measured at six days before MCAO. The tank had a diameter of $100 \mathrm{~cm}$ and an altitude of $50 \mathrm{~cm}$. The platform was placed $0.5 \mathrm{~cm}$ beneath the surface of the water. Each trial was performed for $90 \mathrm{~s}$ or until the mouse arrived on the platform. PMC-12-treated mice received daily oral administration at the doses of 100 and $500 \mathrm{mg} / \mathrm{kg}$ for three weeks after MCAO, while mice in the control and vehicle groups were only given distilled water at the same intervals. After final administration, results of the experiment were recorded using SMART 2.5.18 (Panlab S.L.U.).

\section{Data analysis}

All data were expressed as mean \pm SEM and analyzed using the SigmaStat statistical program version 11.2 (Systat Software, San Jose, CA, USA). Statistical comparisons were performed using one-way analysis of variance (ANOVA) for repeated measures followed by Tukey's test of least significant difference. A $P$-value $<0.05$ was considered to indicate a statistically significant result. The median effective dose $\left(E_{50}\right)$ value of PMC-12 (in vitro experiments) was derived from dose-response curve.

\section{Results}

\section{HPLC analysis of PMC-12}

HPLC conditions, particularly the mobile phase and its elution program, are important for determination of the compound in the biological matrix. In this study, we
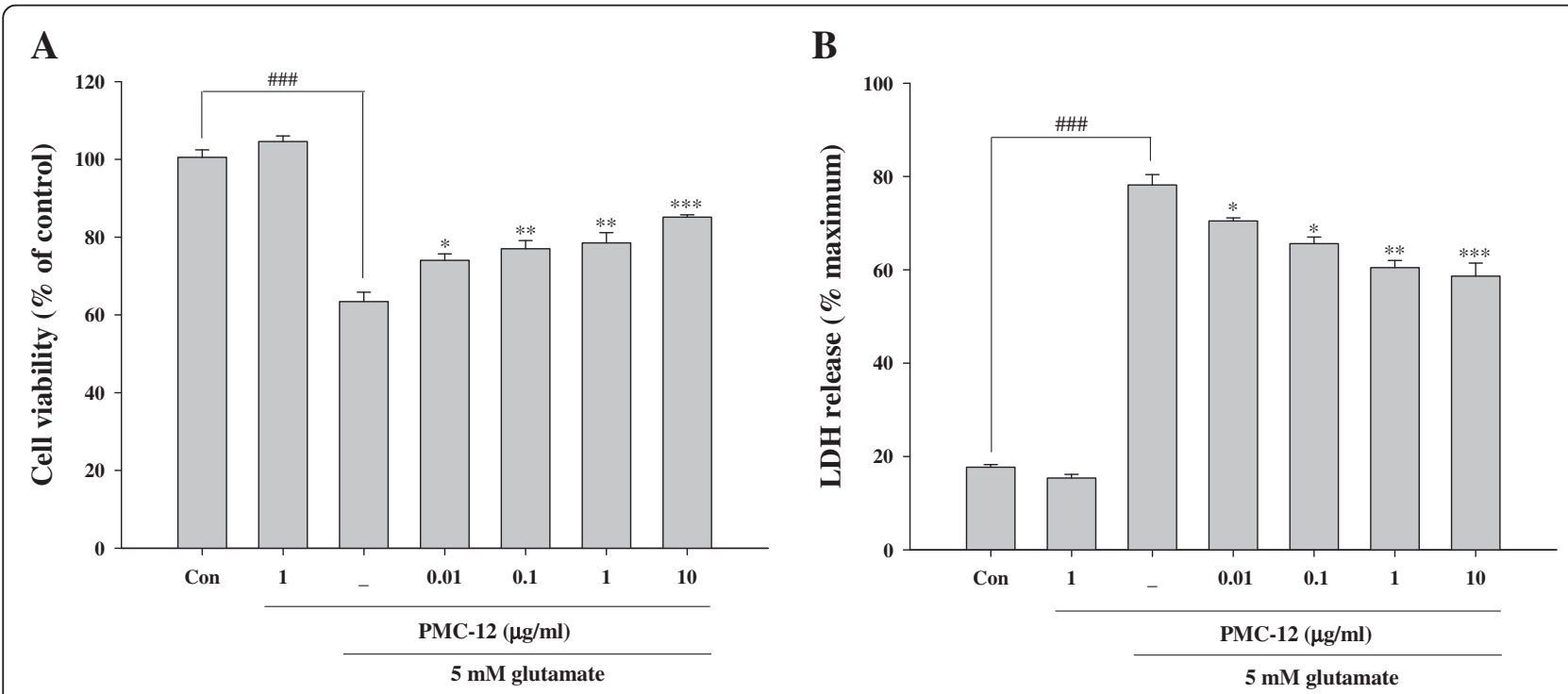

Fig. 2 Protective effects of PMC-12 against glutamate-induced cell death in HT22 cells. Cell viability and toxicity were determined by MTT (a) and LDH assay (b). Cells were pretreated with $0.01,0.1,1$, and $10 \mu \mathrm{g} / \mathrm{ml}$ of PMC-12 for $24 \mathrm{~h}$, followed by exposure to $5 \mathrm{mM}$ glutamate for 24 h. ${ }^{\# \# \#} P<0.001$ vs. control; ${ }^{*} P<0.05,{ }^{*} P<0.01$ and ${ }^{* *} P<0.001$ vs. glutamate-treated cells. All data are represented as the mean \pm SEM of three independent experiments 
found that a mobile phase consisting of acetonitrile and containing $\mathrm{H}_{2} \mathrm{O}$ can separate THS, DISS, and catalpol (Fig. 1). The HPLC conditions developed in this study produced full peak-to-baseline resolution of the major active THS, DISS, and catalpol present in PMC-12. Based on UV maximal absorption, we detected THS and DISS at $254 \mathrm{~nm}$ and catalpol at $203 \mathrm{~nm}$ for quantitative analysis. The contents of THS, DISS, and catalpol in PMC-12 were $3.085 \pm 0.271 \%$, $0.352 \pm 0.058 \%$, and $0.785 \pm 0.059 \%$, respectively. Linear calibration curve showed good linear regression $\left(r^{2}>0.999\right)$ within test ranges; the LOD $(\mathrm{S} / \mathrm{N}=3)$ and the LOQ $(\mathrm{S} / \mathrm{N}=10)$ were less than 1.5 and $4.5 \mu \mathrm{g}$ at $254 \mathrm{~nm}$ for THS and DISS and at $203 \mathrm{~nm}$ for the catalpol (Table 1).
Pretreatment with PMC-12 reduces glutamate-induced neuronal toxicity in $\mathrm{HT} 22$ cells

Exposure of cells to glutamate resulted in reduced cell viability of approximately $36.5 \%$ compared with the control. Pretreatment with PMC-12 at a concentration range of 0.01 to $10 \mu \mathrm{g} / \mathrm{ml}\left(E_{50}=0.32 \mu \mathrm{g} / \mathrm{ml} \mathrm{PMC-12}\right)$ resulted in significantly reduced glutamate-induced cytotoxicity in a dose-dependent manner (Fig. 2a). The levels of LDH release showed a significant increase to $77.8 \%$ after exposure to glutamate, while pretreatment with PMC-12 resulted in a marked decrease of glutamateinduced release of LDH (Fig. 2b). These results suggest that pretreatment with PMC-12 exerts a potent neuroprotective effect against oxidative toxicity caused by exposure of HT22 cells to glutamate.

A
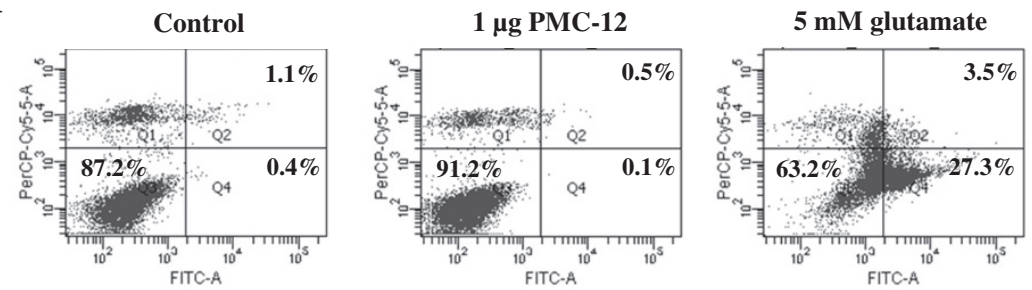

$5 \mathrm{mM}$ glutamate

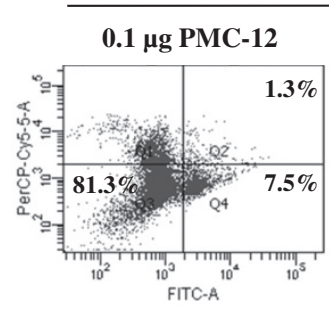

B

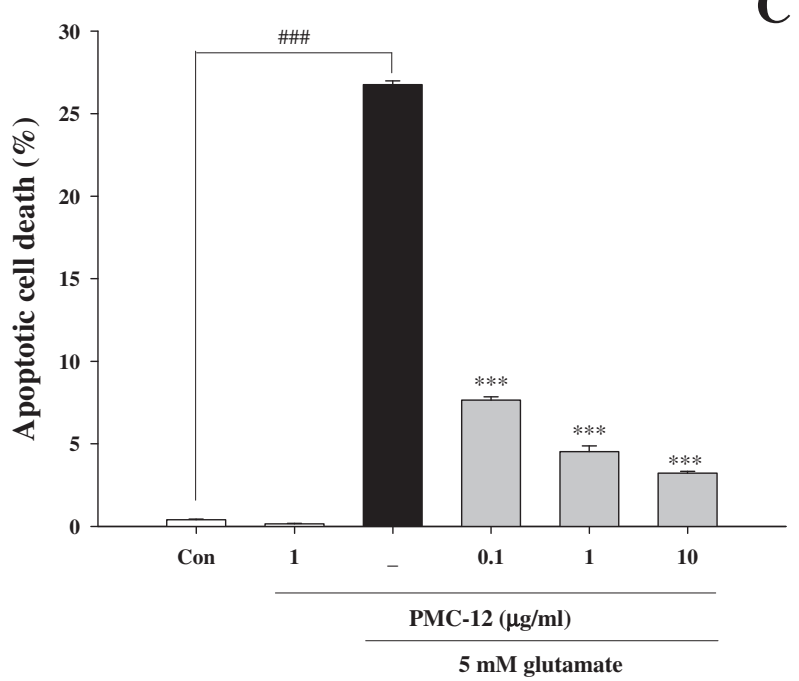

C

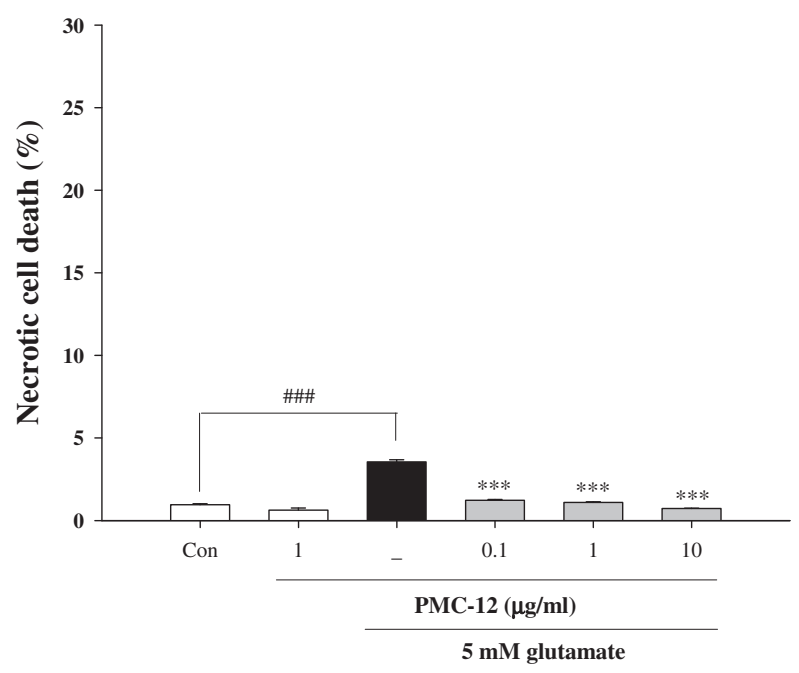

Fig. 3 Protective effect of PMC-12 on types of cell death in HT22 cells. Cells were pretreated with $0.1,1$, or $10 \mu \mathrm{g} / \mathrm{ml}$ PMC-12 for 24 h, followed by exposure to $5 \mathrm{mM}$ glutamate for $24 \mathrm{~h}$. Representative flow cytometric analysis scatter-grams of Annexin V/PI staining (a) and quantitative analysis of the histograms (b and $\mathbf{c}$ ). ${ }^{\# \#} P<0.001$ vs. control; ${ }^{* * *} P<0.001$ vs. glutamate-treated cells. All data are represented as the mean \pm SEM of three independent experiments 


\section{Pretreatment with PMC-12 inhibits glutamate-induced apoptotic cell death in HT22 cells}

We performed flow cytometry analysis using Annexin V/PI staining in order to characterize the types of neuronal death. Concentrations of $0.1,1$, and $10 \mu \mathrm{g} / \mathrm{ml}$ of PMC-12 were selected for testing. After exposure to glutamate, cells were likely to undergo apoptotic cell death rather than necrotic death, however, pretreatment with PMC-12 resulted in a marked decrease in the apoptotic population (Fig. 3). These results suggest that pretreatment with PMC-12 exerts a neuroprotective effect through inhibition of glutamate-induced apoptotic cell death.

\section{Pretreatment with PMC-12 inhibits glutamate-induced production of ROS in HT22 cells}

Treatment of HT22 cells with glutamate resulted in increased production of ROS. However, pretreatment with PMC-12 resulted in a significant decrease in ROS production, which prevented elevation of ROS level caused by exposure to glutamate (Fig. 4a). We also performed staining with Hoechst 33342 to confirm morphological changes by glutamate-induced oxidative toxicity. Our result showed that PMC-12 protected against apoptotic cell death by production of ROS after exposure to glutamate (Fig. 4b). When cells were treated with $10 \mu \mathrm{M}$ of intracellular $\mathrm{Ca}^{2+}$ chelator BAPTA-AM and $1.5 \mathrm{mM}$ of extracellular $\mathrm{Ca}^{2+}$ chelator EGTA, both inhibitors caused a significant reduction in the levels of glutamate-induced production of ROS. However, no change in ROS production was observed in cells treated with a combination of $\mathrm{Ca}^{2+}$ chelators and PMC-12 compared to cells treated with PMC-12 alone followed by exposure to glutamate (Fig. 5). These results suggest that PMC-12 suppresses glutamate-induced oxidative stress by blocking ROS production, which may be related to an indirect $\mathrm{Ca}^{2+}$ pathway.

\section{Pretreatment with PMC-12 enhances mature BDNF expression and CREB phosphorylation via p38 MAPK and PI3K in HT22 cells}

Levels of phosphorylated p38 MAPK and dephosphorylated PI3K were significantly decreased by treatment with either PMC-12 or anti-oxidant NAC compared to glutamate-treated cells. Protein levels of mature BDNF and CREB phosphorylation were significantly increased by treatment with either PMC-12 or NAC (Fig. 6a). When cells were treated with PMC-12, NAC, or intracellular $\mathrm{Ca}^{2+}$ inhibitor BAPTA-AM, combination treatment resulted in markedly reduced levels of phosphorylated p38 MAPK and dephosphorylated PI3K compared to other cells. The combination treatment of cells also resulted

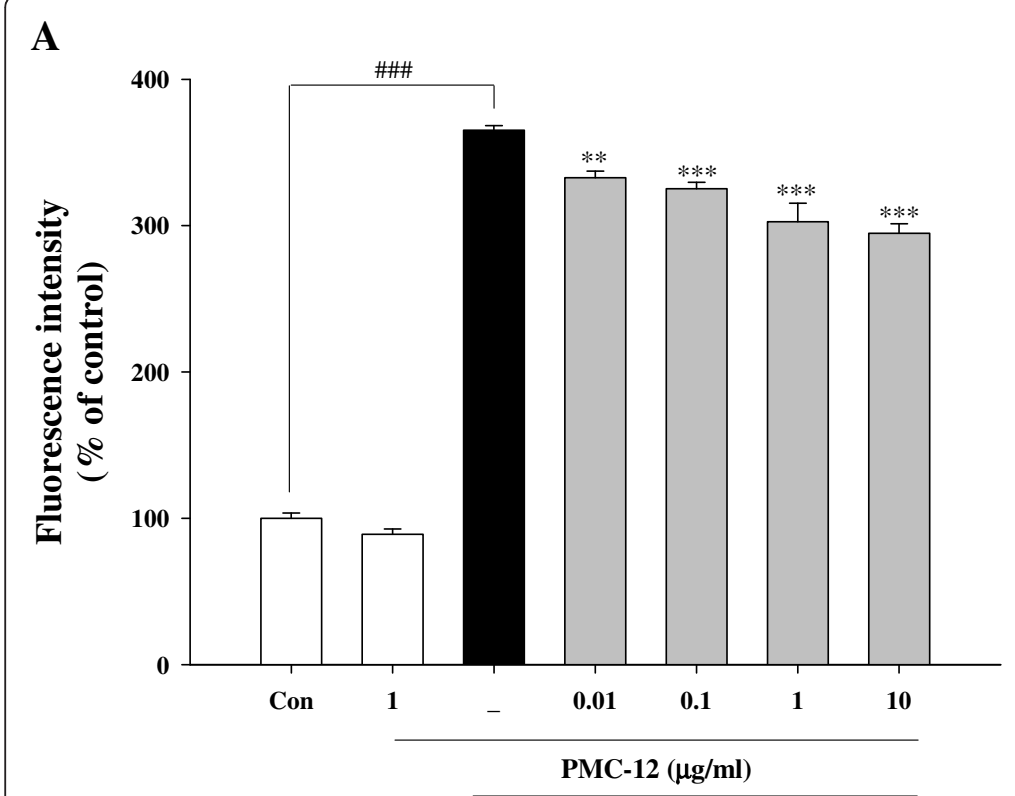

B

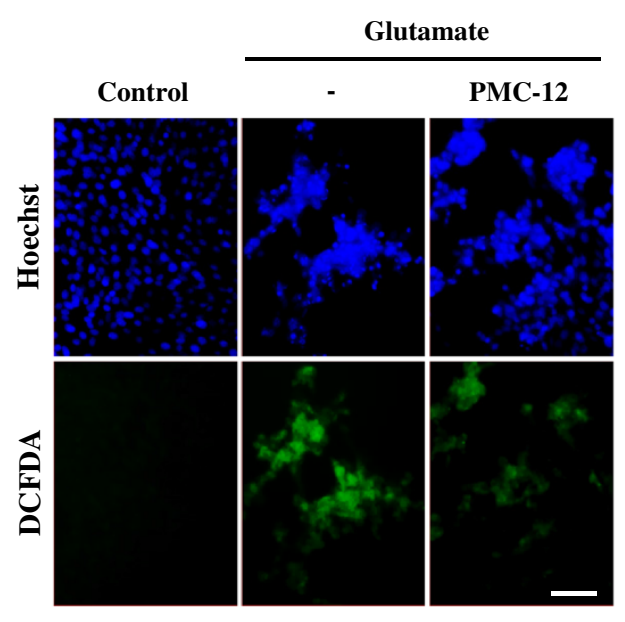

$5 \mathrm{mM}$ glutamate

Fig. 4 Protective effect of PMC-12 on ROS generation in glutamate-treated HT22 cells. Cells were pretreated with $0.01,0.1,1$, or $10 \mu \mathrm{g} / \mathrm{ml}$ of PMC-12 for $24 \mathrm{~h}$, followed by exposure to $5 \mathrm{mM}$ glutamate for $24 \mathrm{~h}$. The oxidation sensitive fluorescence dye, carboxy- $\mathrm{H}_{2} \mathrm{DCFDA}(20 \mu \mathrm{M})$, was used in measurement of ROS levels. Production of ROS was analyzed using a fluorescence plate reader (a) and fluorescence microscope (b). In addition, apoptotic nuclei were observed after staining with Hoechst 33342 for detection of apoptosis morphologically (b). ${ }^{\# \# \#} P<0.001$ vs. control; ${ }^{* * P}<0.01$ and ${ }^{* *} P<0.001$ vs. glutamate-treated cells. All data are represented as the mean \pm SEM of three independent experiments. Scale bars $=50 \mu \mathrm{m}$ 


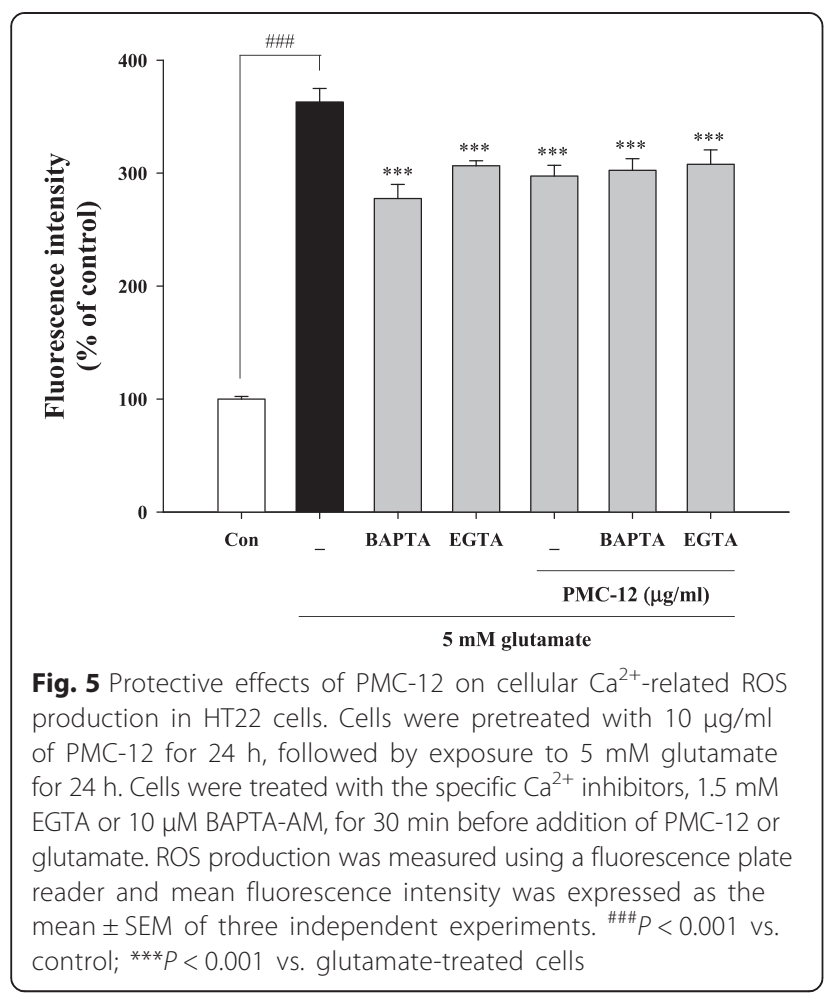

in elevation of decreased protein levels of mature BDNF and CREB phosphorylation after exposure to glutamate (Fig. 6b). These results suggest that neuroprotective effects of PMC-12 may be regulated by both p38 MAPK and PI3K signaling with mature BDNF expression and CREB phosphorylation, and these effects may be related to ROS accumulation and $\mathrm{Ca}^{2+}$ influx.

Treatment with PMC-12 enhances mature BDNF expression and CREB phosphorylation in the hippocampus of MCAO mice

At 26 days after MCAO, positive neuronal cells of pCREB and mature BDNF in the hippocampal CA1 and dentate gyrus (DG) region were counted after immunofluorescence staining. Post-treatment with PMC-12 followed by $\mathrm{MCAO}$ surgery resulted in a significant increase in the number of double-positive cells of pCREB/ NeuN or mature BDNF/NeuN in the CA1 and DG region of the ipsilateral hippocampus compared to the MCAO group (Fig. 7). These results suggest a possible association of the protective effects of PMC-12 with neuronal mature BDNF expression and CREB phosphorylation in the hippocampus of MCAO mice.

\section{Treatment with PMC-12 ameliorates spatial memory impairment in MCAO mice}

Spatial memory was assessed using the water maze test. MCAO mice took a longer time on average to find the platform than the basal group. However, PMC-12-administered mice attained a significantly lower time at both concentrations from 22 to 25 days after MCAO compared to the vehicle group (Fig. 8). In particular, it has shown that a low dose $(100 \mathrm{mg} / \mathrm{kg})$ of PMC-12 is enough for improvement of the damaged memory function. These results suggest that treatment

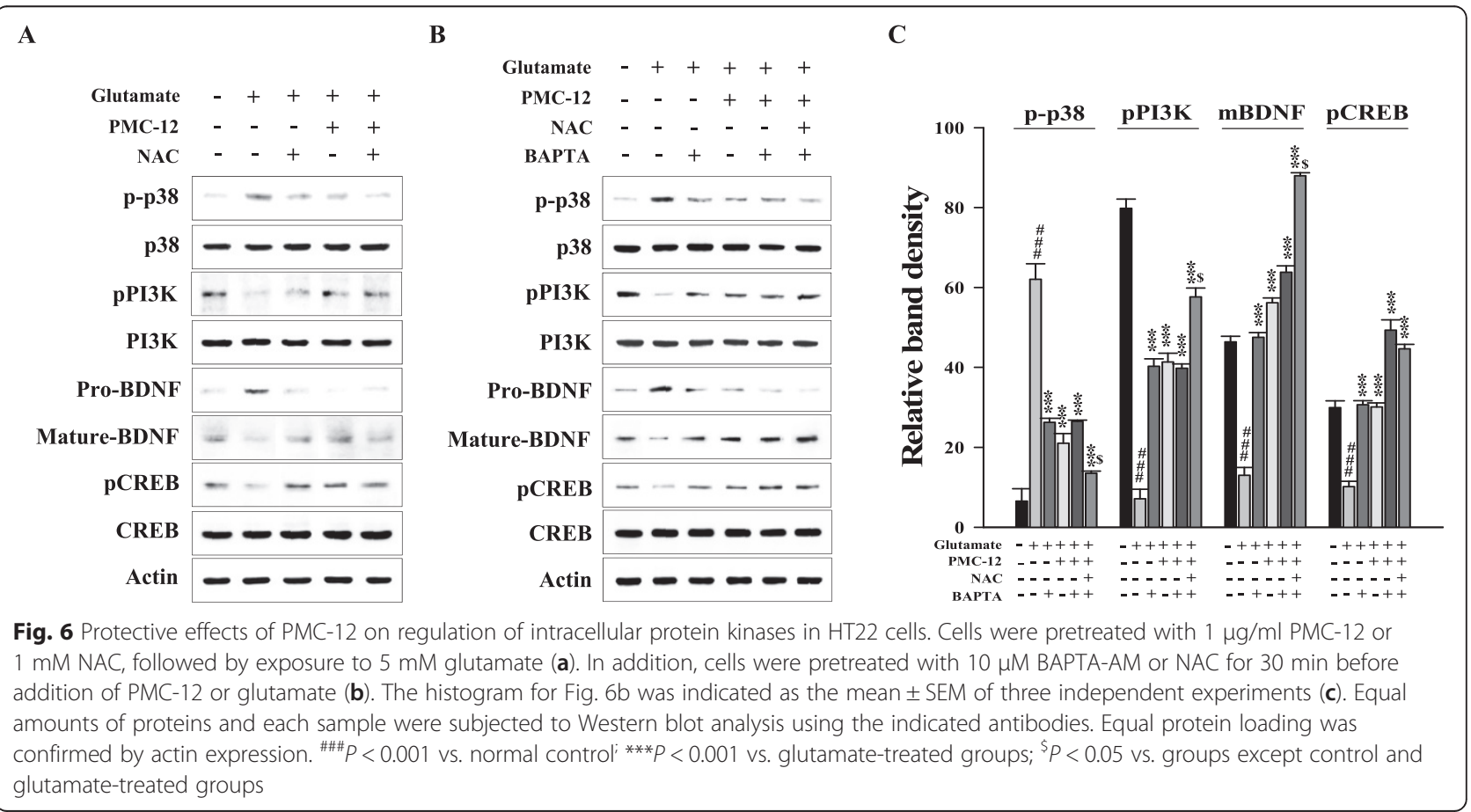




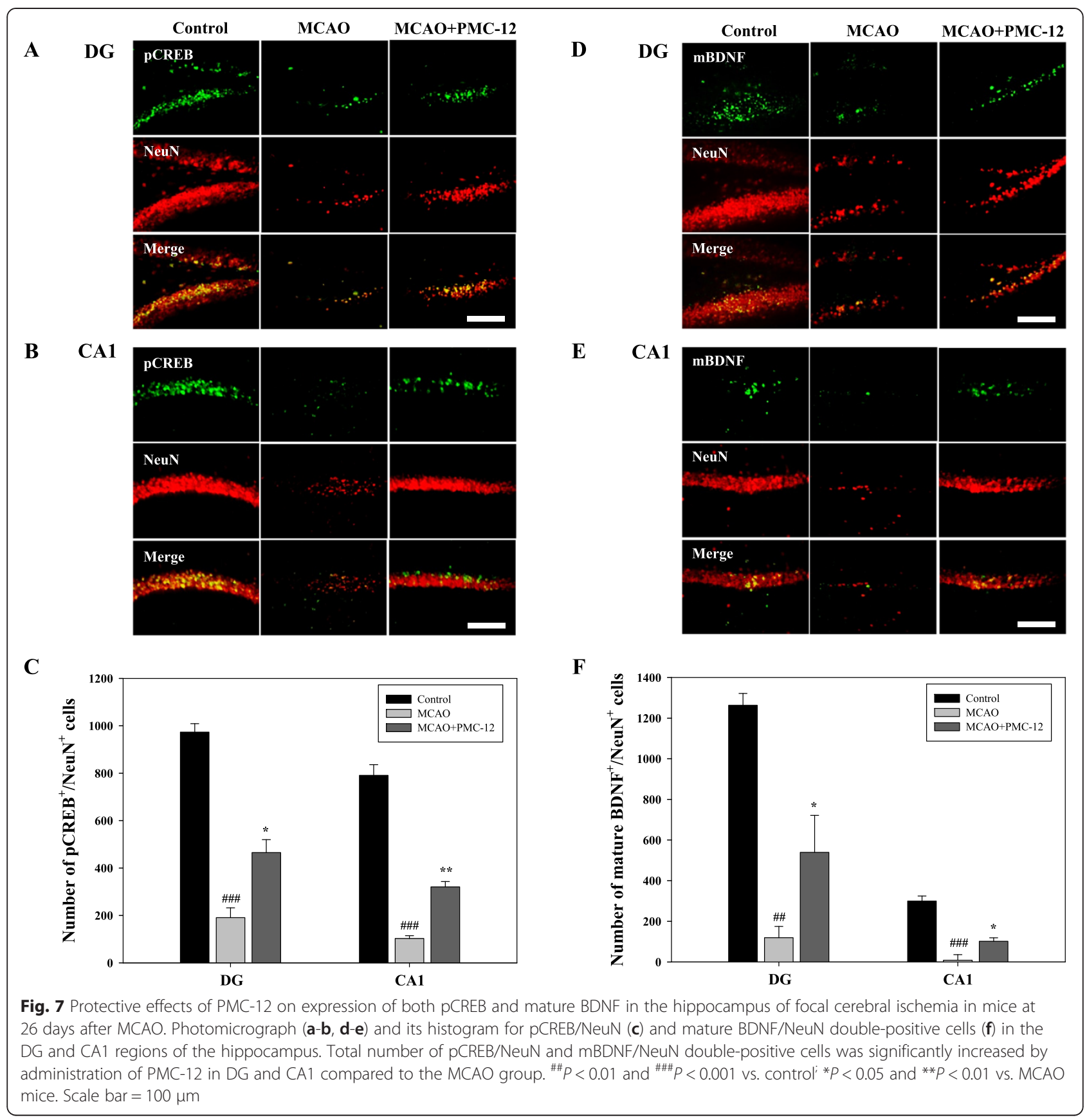

with PMC-12 may induce beneficial effects for improvement of memory function in a focal cerebral ischemia model.

\section{Discussion}

Traditional medical literature can be used to identify and shortlist herbs and combinations of herbs for further experimental and clinical research [24]. We have used a systematic method for screening and evaluating citations from the traditional Korean medicine literature, Dongeuibogam. In a screening exercise performed using
HT22 hippocampal cells for selection of functional herbs on memory impairment, among many herbal candidates, we found that Polygonum multiflorum exhibited prominent neuroprotective effects.

Our previous results demonstrated that extracts from Polygonum multiflorum exert significant anti-apoptotic effects against glutamate-induced neurotoxicity [25, 26] and protect against cerebral ischemic damage via regulation of endothelial nitric oxide [27]. However, extracts of Polygonum multiflorum alone had a partial blocking effect against neuronal damage. 


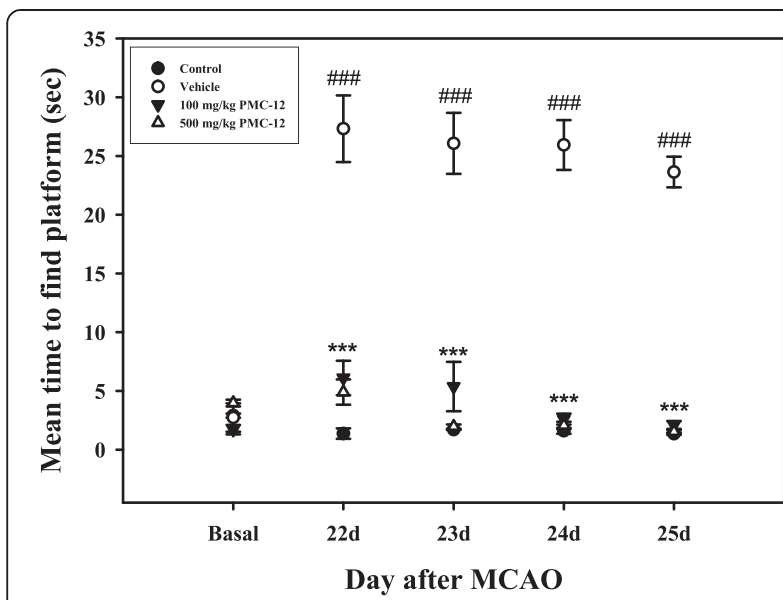

Fig. 8 Beneficial effects of PMC-12 on the spatial memory function in MCAO mice. Morris water maze test was performed from $22 \mathrm{~d}$ to $25 \mathrm{~d}$ after MCAO. Administration of PMC-12 resulted in significantly improved memory function of MCAO mice during the late phase of the experiment. There was no significant differences in the results by two different doses (100 and $500 \mathrm{mg} / \mathrm{kg}$ ) of PMC-12. Mean \pm SEM. $\# \# P<0.001$ vs. control; ***P $<0.001$ vs. MCAO mice (vehicle)

To enhance the potential beneficial effects of Polygonum multiflorum, we analyzed 4,014 herbal prescriptions mentioned in Dongeuibogam and noted 19 multiherb formulae, including the roots of Rehmannia glutinosa, Polygala tenuifolia, and Acorus gramineus. These 19 multiherbs are commonly used in treatment of mental and physical weakness of the elderly.

We prepared PMC-12 with Polygonum multiflorum base and above multiherb formulae to enhance medical efficiency. In a further screening exercise performed using a focal cerebral ischemia model, PMC-12 had marked effects on the decline of infarct size compared with Polygonum multiflorum extract alone. Thus, in the current study, we investigated the beneficial effects of herbal prescription, PMC-12, on hippocampal neurons and spatial memory deficits in mice.

Exposure to glutamate causes neuronal cell death via non-receptor-mediated oxidative stress in hippocampal HT22 cells $[28,29]$. Increased levels of $\mathrm{Ca}^{2+}$ and ROS caused by exposure to glutamate lead to both apoptotic and necrotic cell death $[6,30,31]$. Since alteration of $\mathrm{Ca}^{2+}$ signaling is involved in cell death, it can increase ROS production [32-34].

In the current study, treatment with PMC-12 resulted in reduction of apoptotic cell death with suppression of ROS accumulation; PMC-12 may contribute to neuronal survival against glutamate-induced oxidative toxicity related to cellular content of ROS and $\mathrm{Ca}^{2+}$. However, in treatment with PMC-12, ROS production was not significantly diminished in a concentration-dependent manner and cells were effectively protected for an additional 24 after removal of PMC-12. The beneficial effect of PMC-12 on hippocampal cells may not be attributable to its direct control of ROS accumulation and $\mathrm{Ca}^{2+}$ influx. With anti-oxidative activities, PMC-12 may contribute to other protective pathways, including endogenous kinases.

Neuroprotective effects under oxidative stress are mediated by regulation of MAPK and PI3K signaling pathways, leading to cell death or survival in a variety of neurodegenerative disorders [35-37]. In particular, roles of p38 MAPK signaling in neuronal death $[38,39]$ and activation of PI3K in neuroprotection [10,37] play an essential role under oxidative stress conditions. Our results showed that neuroprotective effects of PMC-12 are regulated by signaling pathways of p38 MAPK and PI3K against glutamate-induced oxidative cell death.

CREB, an important transcription factor implicated in control of adaptive neuronal responses, contributes to several critical functions of BDNF-mediated cell survival [40, 41]. The impaired CREB phosphorylation in hippocampus may be a pathological component in neurodegenerative disorders [42, 43]. BDNF has recently been recognized as a potent modulator capable of regulating a wide repertoire of neuronal functions [44]. Among two forms of extracellular BDNF, pro- and mature BDNF, mature BDNF is essential in protection of neonatal or developing brain from ischemia injury as well as neuronal cells, whereas pro-BDNF may induce neuronal death [44-48]. In accordance with previous studies, cells treated with $\mathrm{PMC}-12$ recovered protein levels of mature BDNF and CREB phosphorylation caused by glutamate. These results suggest that neuroprotective effects of PMC-12 may be regulated by both mature BDNF expression and CREB phosphorylation.

Memory improvement is indicative of the structural and functional hippocampal plastic changes including its expression of BDNF [22]. To confirm involvement of mature BDNF and CREB activation in neuroprotection of PMC-12, we performed in vivo study using a mild ischemic mouse model [22, 23]. Immunohistochemistry results of treatment with PMC-12 for three weeks in MCAO mice indicated significant expression in the CA1 and DG regions of the hippocampus, suggesting that PMC-12 may prevent neuronal death via signaling pathways of both mature BDNF expression and CREB phosphorylation.

In addition, we applied a behavioral test, Morris water maze, which assesses MCAO-induced deficits of learning and memory. Previous report showed that a short duration of 60 min MCAO instead of $2 \mathrm{~h}$ does not result in concomitant sensorimotor deficits in mice [23, 49]. Thus $30 \mathrm{~min}$ MCAO was conducted to avoid the influence of sensorimotor deficit on the performance of the mice in our Morris water maze test. Treatment with PMC-12 resulted in attainment of a significantly lower 
time from 22 to 25 days after MCAO compared with the vehicle group. These findings suggest that PMC-12 may be a good candidate for recovery of damaged learning and memory function in a focal cerebral ischemia model.

Our study did not investigate the main functional components of multiherb formula PMC-12. However, phenolic constituents are well known as major active components of Polygonum multiflorum [50] and tetrahydroxystilbene-glucoside identified from this herb promotes long-term potentiation inductions contributing to enhancement of learning and memory in mice models $[51,52]$. In line with these studies, our HPLC analysis also showed that $2,3,5,4^{\prime}$-tetrahydroxystilbene-2-O- $\beta$-Dglucoside is one of the main components of multiherb formula PMC-12. However, medical herbs have diverse roles within multiherb formulae according to well-known perspectives of traditional Korean medicine. Some herbs target the primary disorder and others aim to alleviate secondary symptoms such as absorption or counting undesirable effects of other herbs $[24,53]$. PMC-12 may enhance memory function to target primary neuroprotective effects and other secondary symptoms by diverse roles within multiherb formulae.

\section{Conclusions}

PMC-12 protects against hippocampal neuronal cell death via inhibition of $\mathrm{Ca}^{2+}$-related accumulation of ROS and these effects regulate through the signaling pathways of p38 MAPK and PI3K associated with mature BDNF expression and CREB phosphorylation. PMC-12 may also modulate recovery of memory function via mature BDNF and CREB against cerebral ischemic stroke. These results have shown that multiherb formula PMC-12 has potential applications as a useful therapeutic strategy in memory impairment of brain disorders.

\section{Competing interests}

The authors declare that there are no financial competing interests.

\begin{abstract}
Authors' contributions
SMA and BTC designed the study. SMA, YRK and HNK performed the experiments and analyzed data. SMA and BTC wrote the manuscript. YWC, JWL, CMK, JUB and HKS corrected the manuscript. All authors read and approved the final manuscript.
\end{abstract}

\section{Acknowledgement}

This work was supported by the R\&D program of MOTIE/KIAT (N0000697, Establishment of Infra Structure for Anti-aging Industry Support).

\footnotetext{
Author details

'Department of Korean Medical Science, School of Korean Medicine, Pusan National University, Yangsan 626-870, Republic of Korea. ${ }^{2}$ Department of Horticultural Bioscience, College of Natural Resource and Life Science, Pusan National University, Miryang 626-706, Republic of Korea. ${ }^{3}$ Division of Pharmacy, College of Pharmacy, Pusan National University, Busan 609-735, Republic of Korea. ${ }^{4}$ Department of Biochemistry, College of Medicine, Pusan National University, Yangsan 626-870, Republic of Korea. ${ }^{5}$ Division of
}

Humanities and Social Medicine, School of Korean Medicine, Pusan National University, Yangsan 626-870, Republic of Korea. ${ }^{6}$ Division of Meridian and Structural Medicine, School of Korean Medicine, Pusan National University, Yangsan 626-870, Republic of Korea. ${ }^{~}$ Research Center for Anti-aging Technology Development, Pusan National University, Busan 609-735, Republic of Korea.

Received: 30 October 2014 Accepted: 23 June 2015

Published online: 30 June 2015

\section{References}

1. Itua I, Naderali EK. Review: omega-3 and memory function: to eat or not to eat. Am J Alzheimers Dis Other Demen. 2010;25(6):479-82.

2. Lee KY, Jeong EJ, Huh J, Cho N, Kim TB, Jeon BJ, et al. Cognition-enhancing and neuroprotective activities of the standardized extract of Betula platyphylla bark and its major diarylheptanoids. Phytomedicine. 2012;19(14):1315-20.

3. Debette $\mathrm{S}$. Vascular risk factors and cognitive disorders. Rev Neurol (Paris). 2013;169(10):757-64.

4. Kempf SJ, Buratovic S, von Toerne C, Moertl S, Stenerlow B, Hauck SM, et al. lonising radiation immediately impairs synaptic plasticity-associated cytoskeletal signalling pathways in HT22 cells and in mouse brain: an in vitro/in vivo comparison study. PLoS One. 2014;9(10):e110464.

5. Murphy TH, Miyamoto M, Sastre A, Schnaar RL, Coyle JT. Glutamate toxicity in a neuronal cell line involves inhibition of cystine transport leading to oxidative stress. Neuron. 1989;2(6):1547-58.

6. Stanciu M, Wang Y, Kentor R, Burke N, Watkins S, Kress G, et al. Persistent activation of ERK contributes to glutamate-induced oxidative toxicity in a neuronal cell line and primary cortical neuron cultures. J Biol Chem. 2000;275(16):12200-6.

7. Zhang $Y$, Bhavnani BR. Glutamate-induced apoptosis in neuronal cells is mediated via caspase-dependent and independent mechanisms involving calpain and caspase-3 proteases as well as apoptosis inducing factor (AIF) and this process is inhibited by equine estrogens. BMC Neurosci. 2006;7:49.

8. Tan S, Schubert D, Maher P. Oxytosis: A novel form of programmed cell death. Curr Top Med Chem. 2001;1(6):497-506.

9. Miyamoto M, Murphy TH, Schnaar RL, Coyle JT. Antioxidants protect against glutamate-induced cytotoxicity in a neuronal cell line. J Pharmacol Exp Ther. 1989;250(3):1132-40.

10. Fukui $M$, Choi HJ, Zhu BT. Mechanism for the protective effect of resveratrol against oxidative stress-induced neuronal death. Free Radic Biol Med. 2010:49(5):800-13.

11. Yang EJ, Park GH, Song KS. Neuroprotective effects of liquiritigenin isolated from licorice roots on glutamate-induced apoptosis in hippocampal neuronal cells. Neurotoxicology. 2013;39:114-23.

12. Choi BH, Hur EM, Lee JH, Jun DJ, Kim KT. Protein kinase Cdelta-mediated proteasomal degradation of MAP kinase phosphatase-1 contributes to glutamate-induced neuronal cell death. J Cell Sci. 2006;119(Pt 7):1329-40.

13. Almeida RD, Manadas BJ, Melo CV, Gomes JR, Mendes CS, Graos MM, et al. Neuroprotection by BDNF against glutamate-induced apoptotic cell death is mediated by ERK and PI3-kinase pathways. Cell Death Differ. 2005;12(10):1329-43.

14. Jain V, Baitharu I, Prasad D, llavazhagan G. Enriched environment prevents hypobaric hypoxia induced memory impairment and neurodegeneration: role of BDNF/PI3K/GSK3beta pathway coupled with CREB activation. PLoS One. 2013;8(5):e62235.

15. Platenik J, Fisar Z, Buchal R, Jirak R, Kitzlerova E, Zverova M, et al. GSK3beta, CREB, and BDNF in peripheral blood of patients with Alzheimer's disease and depression. Prog Neuropsychopharmacol Biol Psychiatry. 2014;50:83-93.

16. Ferrer I, Blanco R, Carmona M. Differential expression of active, phosphorylation-dependent MAP kinases, MAPK/ERK, SAPK/JNK and p38, and specific transcription factor substrates following quinolinic acid excitotoxicity in the rat. Brain Res Mol Brain Res. 2001;94(1-2):48-58.

17. Carlezon Jr WA, Duman RS, Nestler EJ. The many faces of CREB. Trends Neurosci. 2005;28(8):436-45.

18. Kitagawa K. CREB and CAMP response element-mediated gene expression in the ischemic brain. FEBS J. 2007;274(13):3210-7.

19. Scott Bitner R. Cyclic AMP response element-binding protein (CREB) phosphorylation: a mechanistic marker in the development of memory enhancing Alzheimer's disease therapeutics. Biochem Pharmacol. 2012;83(6):705-14 
20. Jamarkattel-Pandit N, Pandit NR, Kim MY, Park SH, Kim KS, Choi H, et al. Neuroprotective effect of defatted sesame seeds extract against in vitro and in vivo ischemic neuronal damage. Planta Med. 2010;76(1):20-6.

21. Koh PO. Ferulic acid prevents cerebral ischemic injury-induced reduction of hippocalcin expression. Synapse. 2013;67(7):390-8.

22. Shih PC, Yang YR, Wang RY. Effects of exercise intensity on spatial memory performance and hippocampal synaptic plasticity in transient brain ischemic rats. PLoS One. 2013;8(10):e78163.

23. Zhang X, Yeung PK, McAlonan GM, Chung SS, Chung SK. Transgenic mice over-expressing endothelial endothelin-1 show cognitive deficit with bloodbrain barrier breakdown after transient ischemia with long-term reperfusion. Neurobiol Learn Mem. 2013;101:46-54.

24. May BH, Lu C, Bennett L, Hugel HM, Xue CC. Evaluating the traditional Chinese literature for herbal formulae and individual herbs used for age-related dementia and memory impairment. Biogerontology. 2012;13(3):299-312.

25. Jang JY, Kim HN, Kim YR, Choi YW, Choi YH, Lee JH, et al. Hexane extract from Polygonum multiflorum attenuates glutamate-induced apoptosis in primary cultured cortical neurons. J Ethnopharmacol. 2013;145(1):261-8.

26. Kim HN, Kim YR, Jang JY, Choi YW, Baek JU, Hong JW, et al. Neuroprotective effects of Polygonum multiflorum extract against glutamate-induced oxidative toxicity in HT22 hippocampal cells. J Ethnopharmacol. 2013;150(1):108-15.

27. Lee SV, Choi KH, Choi YW, Hong JW, Baek JU, Choi BT, et al. Hexane extracts of Polygonum multiflorum improve tissue and functional outcome following focal cerebral ischemia in mice. Mol Med Rep. 2014;9(4):1415-21.

28. Maher P, Davis JB. The role of monoamine metabolism in oxidative glutamate toxicity. J Neurosci. 1996;16(20):6394-401.

29. Lee MS, Chao J, Yen JC, Lin LW, Tsai FS, Hsieh MT, et al. Schizandrin protects primary rat cortical cell cultures from glutamate-induced apoptosis by inhibiting activation of the MAPK family and the mitochondria dependent pathway. Molecules. 2012;18(1):354-72.

30. Tan S, Sagara $Y$, Liu $Y$, Maher $P$, Schubert $D$. The regulation of reactive oxygen species production during programmed cell death. J Cell Biol. 1998;141(6):1423-32.

31. Tan S, Wood M, Maher P. Oxidative stress induces a form of programmed cell death with characteristics of both apoptosis and necrosis in neuronal cells. J Neurochem. 1998;71(1):95-105.

32. Isaev NK, Zorov DB, Stelmashook EV, Uzbekov RE, Kozhemyakin MB, Victorov IV. Neurotoxic glutamate treatment of cultured cerebellar granule cells induces Ca2+ -dependent collapse of mitochondrial membrane potential and ultrastructural alterations of mitochondria. FEBS Lett. 1996;392(2):143-7.

33. Macho A, Hirsch T, Marzo I, Marchetti P, Dallaporta B, Susin SA, et al. Glutathione depletion is an early and calcium elevation is a late event of thymocyte apoptosis. J Immunol. 1997;158(10):4612-9.

34. Randall RD, Thayer SA. Glutamate-induced calcium transient triggers delayed calcium overload and neurotoxicity in rat hippocampal neurons. J Neurosci. 1992;12(5):1882-95.

35. Anderson CN, Tolkovsky AM. A role for MAPK/ERK in sympathetic neuron survival: protection against a p53-dependent, JNK-independent induction of apoptosis by cytosine arabinoside. J Neurosci. 1999;19(2):664-73.

36. Borsello T, Forloni G. JNK signalling: a possible target to prevent neurodegeneration. Curr Pharm Des. 2007;13(18):1875-86.

37. Qin R, Li X, Li G, Tao L, Li Y, Sun J, et al. Protection by tetrahydroxystilbene glucoside against neurotoxicity induced by MPP+: the involvement of PI3K/Akt pathway activation. Toxicol Lett. 2011;202(1):1-7.

38. Lasa M, Abraham SM, Boucheron C, Saklatvala J, Clark AR. Dexamethasone causes sustained expression of mitogen-activated protein kinase (MAPK) phosphatase 1 and phosphatase-mediated inhibition of MAPK p38. Mol Cell Biol. 2002;22(22):7802-11.

39. Zhao L, Liu X, Liang J, Han S, Wang Y, Yin Y, et al. Phosphorylation of p38 MAPK mediates hypoxic preconditioning-induced neuroprotection against cerebral ischemic injury via mitochondria translocation of $\mathrm{BCl}-\mathrm{xL}$ in mice. Brain Res. 2013;1503:78-88.

40. Bonni A, Brunet A, West AE, Datta SR, Takasu MA, Greenberg ME. Cell survival promoted by the Ras-MAPK signaling pathway by transcription-dependent and -independent mechanisms. Science. 1999;286(5443):1358-62.

41. Sakamoto K, Karelina K, Obrietan K. CREB: a multifaceted regulator of neuronal plasticity and protection. J Neurochem. 2011;116(1):1-9.
42. Yamamoto-Sasaki M, Ozawa H, Saito T, Rosler M, Riederer P. Impaired phosphorylation of cyclic AMP response element binding protein in the hippocampus of dementia of the Alzheimer type. Brain Res. 1999;824(2):300-3.

43. Dineley KT, Westerman M, Bui D, Bell K, Ashe KH, Sweatt JD. Beta-amyloid activates the mitogen-activated protein kinase cascade via hippocampal alpha7 nicotinic acetylcholine receptors: In vitro and in vivo mechanisms related to Alzheimer's disease. J Neurosci. 2001;21(12):4125-33.

44. Chen A, Xiong $L$, Tong $Y$, Mao M. The neuroprotective roles of BDNF in hypoxic ischemic brain injury. Biomed Rep. 2013;1(2):167-76.

45. Thomas K, Davies A. Neurotrophins: a ticket to ride for BDNF. Curr Biol. 2005;15(7):R262-264.

46. Koshimizu H, Kiyosue K, Hara T, Hazama S, Suzuki S, Uegaki K, et al. Multiple functions of precursor BDNF to CNS neurons: negative regulation of neurite growth, spine formation and cell survival. Mol Brain. 2009;2:27.

47. Segawa M, Morinobu S, Matsumoto T, Fuchikami M, Yamawaki S. Electroconvulsive seizure, but not imipramine, rapidly up-regulates pro-BDNF and t-PA, leading to mature BDNF production, in the rat hippocampus. Int J Neuropsychopharmacol. 2013;16(2):339-50.

48. Sun XL, Chen BY, Xia Y, Wang JJ, Chen LW. Functional switch from pro-neurotrophins to mature neurotrophins. Curr Protein Pept Sci. 2013;14(7):617-25

49. Li W, Huang R, Shetty RA, Thangthaeng N, Liu R, Chen Z, et al. Transient focal cerebral ischemia induces long-term cognitive function deficit in an experimental ischemic stroke model. Neurobiol Dis. 2013;59:18-25.

50. Qiu X, Zhang J, Huang Z, Zhu D, Xu W. Profiling of phenolic constituents in Polygonum multiflorum Thunb. by combination of ultra-high-pressure liquid chromatography with linear ion trap-Orbitrap mass spectrometry. J Chromatogr A. 2013;1292:121-31.

51. Wang T, Gu J, Wu PF, Wang F, Xiong Z, Yang YJ, et al. Protection by tetrahydroxystilbene glucoside against cerebral ischemia: involvement of JNK, SIRT1, and NF-kappaB pathways and inhibition of intracellular ROS/RNS generation. Free Radic Biol Med. 2009;47(3):229-40.

52. Wang T, Yang YJ, Wu PF, Wang W, Hu ZL, Long LH, et al. Tetrahydroxystilbene glucoside, a plant-derived cognitive enhancer, promotes hippocampal synaptic plasticity. Eur J Pharmacol. 2011;650(1):206-14.

53. Bensky D, Barolet R. Chinese Herbal Medicine: Formulas and Strategies Seattle: Eastland Press; 1990.

\section{Submit your next manuscript to BioMed Central and take full advantage of:}

- Convenient online submission

- Thorough peer review

- No space constraints or color figure charges

- Immediate publication on acceptance

- Inclusion in PubMed, CAS, Scopus and Google Scholar

- Research which is freely available for redistribution 